\title{
Outcomes of ovarian transposition in gynaecological cancers; a systematic review and meta-analysis
}

\author{
Kumar Gubbala ${ }^{1 \dagger}$, Alex Laios ${ }^{2^{*} \dagger}$, Ioannis Gallos ${ }^{3}$, Pubudu Pathiraja ${ }^{2}$, Krishnayan Haldar ${ }^{2}$ and Thomas Ind
}

\begin{abstract}
Background: Pelvic irradiation is essential for improving survival in women with pelvic malignancies despite inducing permanent ovarian damage. Ovarian transposition can be performed in premenopausal women in an attempt to preserve ovarian function. As uncertainty occurs over the proportion of women who are likely to benefit from the procedure, we performed a systematic review and meta-analysis of the proportion of women with ovarian function preservation, symptomatic or asymptomatic ovarian cysts and metastatic ovarian malignancy following ovarian transposition.

Methods: Medline, Embase and The Cochrane Library databases were systematically searched for articles published from January 1980 to December 2013. We computed the summary proportions for ovarian function preservation, ovarian cyst formation and metastatic ovarian disease following ovarian transposition by random effects meta-analysis with meta-regression to explore for heterogeneity by type of radiotherapy.

Results: Twenty four articles reporting on 892 women undergoing ovarian transposition were included. In the surgery alone group, the proportion of women with preserved ovarian function was 90\% (95\% Cl 92-99), 87\% (95\% Cl 79-97) of women did not develop ovarian cysts and 100\% (95\% Cl 90-111) did not suffer metastases to the transposed ovaries. In the brachytherapy (BR) \pm surgery group, the proportion of women with preserved ovarian function was $94 \%$ (95\% Cl 79-111), 84\% (95\% Cl 70-101) of women did not develop ovarian cysts and 100\% (95\% Cl 85-118) did not suffer metastases to the transposed ovaries. In the external beam radiotherapy (EBRT) + surgery \pm BR group, the proportion of women with preserved ovarian function was 65\% (95\% Cl 56-74), 95\% (95\% Cl 85-106) of women did not develop ovarian cysts and 100\% (95\% Cl 90-112) did not suffer metastases to the transposed ovaries. Subgroup meta-analysis revealed transposition to the subcutaneous tissue being associated with higher ovarian cyst formation rate compared to the "traditional" transposition.
\end{abstract}

Conclusion: Ovarian transposition is associated with significant preservation of ovarian function and negligible risk for metastases to the transposed ovaries despite common incidence of ovarian cysts.

\section{Introduction}

Ovarian transposition (OT) has proven invaluable for ovarian function preservation in patients with pelvic malignancies requiring pelvic irradiation. First described in 1958 [1], it was initially performed at laparotomy until more recently when laparoscopic and robotic techniques have been described $[2,3]$. Surgical approaches include

\footnotetext{
*Correspondence: alex.laios@obs-gyn.ox.ac.uk

${ }^{\dagger}$ Equal contributors

${ }^{2}$ Department of Gynaecologic Oncology, Royal Marsden Hospital NHS Trust, London, UK

Full list of author information is available at the end of the article
}

intra- and retroperitoneal transposition on or lateral to the psoas muscle, the paracolic gutters, percutaneous needle transposition of the ovaries and exteriorisation to the subcutaneous fat tissue [4-8].

It has now been established as a simple and reliable method with reduced morbidity [9]. Standard criteria for the preservation and transposition of the ovaries have been proposed [10]. In effect, the procedure is limited to a population of young premenopausal patients with early-stage, operable cervical tumours with a need for primary or adjuvant radiotherapy. It can be additionally performed for ovarian dysgerminomas, vaginal cancers 
but also non-gynaecological malignancies like ependymomas, Hodgkin's disease, sarcomas and rectal carcinomas [11-13].

Ovulation induction and oocyte retrieval can be successfully performed on transposed ovaries [14]. Studies on OT have rendered rather conflicting results, particularly those including patients who never went on to have radiotherapy. Nonetheless, retained ovaries carry a risk for symptomatic ovarian cysts and metastases to the ovaries from the primary site [15]. Yet, significant uncertainty exists regarding the efficacy of this procedure from observational studies with small sample sizes, which makes it difficult to counsel women accordingly. To ascertain the efficacy of OT, we conducted a systematic review and meta-analysis of the proportion of women who underwent OT with ovarian function preservation, symptomatic or asymptomatic ovarian cysts and metastatic ovarian malignancy.

\section{Materials and methods Study Identification}

The population of interest in this review included premenopausal women with a diagnosis of a gynaecological malignancy who might require radiotherapy in addition to surgery. Patients who had OT without the need for adjuvant radiotherapy and who underwent unilateral OT were also included.

The intervention was OT and the outcomes included ovarian function preservation, metastatic ovarian malignancy and symptomatic or asymptomatic ovarian cysts. MEDLINE, EMBASE and The Cochrane Library were searched for articles published between January 1980 and April 2014. We used the following search strategy combining text and Medical Subject and Emtree Headings terms: women OR female AND ovar* transposition' OR oophoropexy AND ovarian preservation OR ovarian function OR premature ovarian failure OR ovarian cysts OR metastases. No language restrictions were applied. Studies of women who had gynaecological surgery for benign indications resulting in ovarian cessation were not included in the review. References of selected studies were searched for articles not identified by the electronic searches, in an attempt to find additional citations. Review articles were not screened for additional citations. Case reports or series with fewer than 3 cases were excluded.

\section{Study selection and data extraction}

The following information were extracted; publication date, type of study, duration of follow up, type of OT, retention of ovarian function, incidence of metastasis, ovarian cysts formation and associated complications. Studies were selected in a 2-stage process. Firstly, titles and abstracts from the electronic searches were screened by 2 independent reviewers (KG and TI) and full manuscripts of all citations that met the predefined selection criteria were obtained. Subsequently these articles were evaluated in full text for each of the 3 objectives to make the final selection. In case of duplicates, the most recent or complete publication was selected. Any disagreements were resolved by consensus or arbitration by a third reviewer (AL). Summary (aggregate) outcome data extracted from each study were created in $2 \times 2$ tables (AL). Preservation of ovarian function was assessed by patient's symptoms and serum FSH, LH, E2 levels. Only patients for which follow up was available were included in the meta-analysis. The Methodological Index for NonRandomized Studies (MINORS), which assesses the quality of the included studies, was implemented [16]. For reporting of results, we followed the recommendations of Meta-analysis of Observational Studies in Epidemiology (MOOSE) [17].

\section{Statistical analysis}

For the analysis of outcomes, we calculated the proportions of women who had their ovarian function preserved, had no ovarian cysts and no metastases in the transposed ovaries per total number of women undergoing OT. We computed the logarithm of the ratio and its corresponding standard error for each of the studies. A meta-analysis with inverse-variance weighting was performed using a random effects model. Forest plots were created for each outcome showing individual study proportions with confidence intervals (CIs) and the overall pool estimate. Heterogeneity was statistically evaluated using the $\mathrm{I}^{2}$ test. For funnel-plot asymmetry, we performed the Egger's weighted regression test. Statistical analyses were performed using Stata 12.0 (Stata Corp, College Station, TX).

\section{Results}

The electronic search strategy initially yielded 396 citations. The selection process for included articles is shown in Figure 1. We retrieved 26 articles for full text examination and we further excluded a review article [18] and an article with unrelated population as it was not referring to gynaecological malignancy [19]. As a result, 24 primary studies, reporting on 892 women who underwent OT were included in this review. The main study characteristics are shown in Table 1. The quality assessment of the studies in the MINORS checklist is shown in Figure 2. All studies were observational. In brief, $7 / 24$ (29.1\%) of studies were prospective including consecutive patients in $21 / 24(87.5 \%)$. There was an adequate definition of outcomes in 20/24 (83.3\%) studies. No studies had a blinded assessment of the outcomes or performed a prospective calculation of sample size. The 


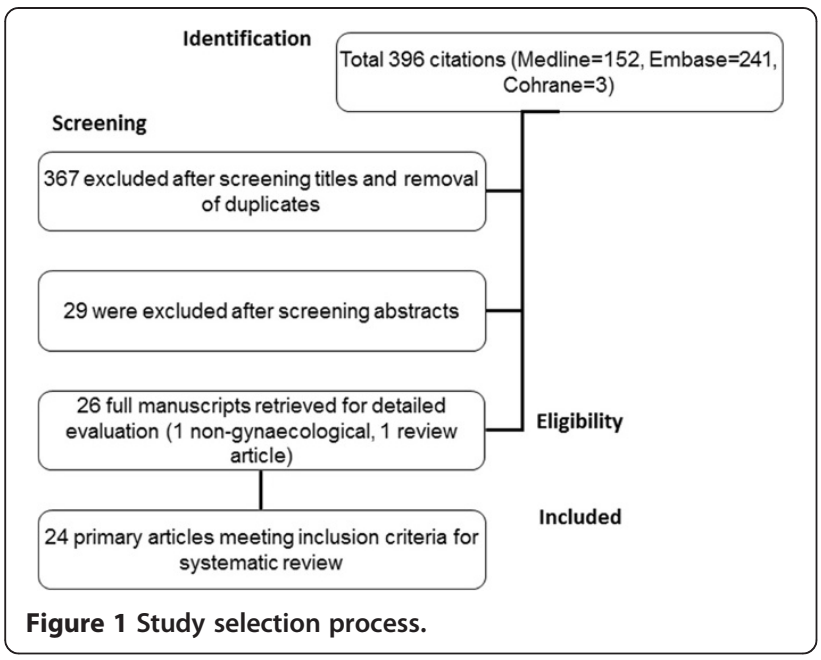

mean follow-up was longer than 12 months in $19 / 24$ (79.1\%) of studies.

In the majority of the studies, the procedure was performed in patients less than 40 years of age. Surgery was by laparotomy or laparoscopy. In 2 studies the ovaries were transposed to the subcutaneous tissue $[8,23]$. The vast majority of patients $(n=828)$ had cervical cancer; 43 patients had vaginal cancer, 10 patients had ovarian dysgerminomas and 7 patients had pelvic sarcomas. There were 4 cases of pelvic lymphomas.

Women included in the analysis had a diagnosis of cancer and their ovaries transposed. A total of 428 women had surgery alone in the form of radical hysterectomy $(\mathrm{RH}) \pm$ pelvic lymphadenectomy $(\mathrm{PLND}) \pm$ upper vaginectomy \pm paraaortic lymph node dissection (PALND) (Group A). 143 had post-operative brachytherapy (BR) (Group B). 321 had post-operative external beam radiotherapy $($ EBRT) \pm BR (Group C). The follow up ranged from 2 to 126 months (Table 1 ).

\section{Preserved ovarian function}

Pooling of results from 18 studies ( $\mathrm{n}=428$ women) that reported ovarian function as an outcome in group A rendered a summary proportion of $90 \%$ (95\% CI 82-99) for ovarian function preservation with no significant variation across the studies $\left(\mathrm{I}^{2}=0.0 \%, \mathrm{p}=0.9\right)$ (Figure 3 ). The summary proportion from 9 studies ( $\mathrm{n}=143$ women) for ovarian function preservation was also $90 \%$ (95\% CI 79-111) for group B with no statistical variation across the studies $\left(I^{2}=0.0 \%, p=1\right)$ (Figure 4). Pooling of results from 23 studies ( $\mathrm{n}=321$ women) in group $\mathrm{C}$ rendered a summary proportion of $65 \%$ (95\% CI 56-74) for ovarian function preservation with no significant variation across the studies $\left(\mathrm{I}^{2}=13.5, \mathrm{p}=0.27\right)$ (Figure 5). For the outcome of ovarian function preservation no statistical significance for small study effects and plot asymmetry was found (Figure 6).

\section{Non metastases to the transposed ovaries}

Pooling of results from 18 studies in group A, 10 studies in group B and 23 studies in group $\mathrm{C}$ reported no metastases to the transposed ovaries (95\% CIs 90-111, 85118 and $90-112$ for groups A, B and C respectively). No significant variation across the studies for the 3 groups was observed $\left(\mathrm{I}^{2}=0.0 \%, \mathrm{p}=1\right)$. In absolute numbers, only 1 study reported 2 recurrences in group A. These 2 patients had adenoid cystic carcinoma and cervical adenocarcinoma respectively. They underwent surgery for recurrent cancer 19 and 27 months after primary RH and both had disseminated disease involving transposed ovaries.

\section{No ovarian cyst formation}

Pooling of results from 18 studies that reported no ovarian cyst formation as an outcome in group A rendered a summary proportion of $87 \%$ for no ovarian cyst formation (95\% CI 79-97). There was significant variation across the studies $\left(\mathrm{I}^{2}=51.9 \%, \mathrm{p}=0.006\right)$. Interestingly, subgroup meta-analysis revealed that women undergoing subcutaneous OT $(\mathrm{n}=2$ studies, weight $=6.61 \%)$ had a $57 \%$ rate of no cyst formation compared to $90 \%$ on those $(\mathrm{n}=16$ studies, weight $=93.4 \%)$ undergoing "traditional" lateral OT (95\% CI 38-85) versus (95\% CI 81-100). However, variation across the studies for both subgroups was significant $\left(\mathrm{I}^{2}=51.9 \%, \mathrm{p}=0.006\right)$ versus $\left(\mathrm{I}^{2}=40.7 \%\right.$, $\mathrm{p}=0.046)$ (Figure 7).

The summary proportion for no ovarian cyst formation in group B ( $\mathrm{n}=10$ studies) was $84 \%(95 \%$ CI $70-101)$, $\left(\mathrm{I}^{2}=0.0 \%, \mathrm{p}=0.885\right)$. No ovarian cyst formation was observed in the subgroup of patients with subcutaneous OT $(\mathrm{n}=1$ study, weight $=0.85 \%)(95 \%$ CI $70-110)$. Pooling of results from 23 studies in group $\mathrm{C}$ rendered a summary proportion of $95 \%$ for no ovarian cyst formation (95\% CI 85-106) with no significant variation across the studies $\left(\mathrm{I}^{2}=0.0 \%, \mathrm{p}=1\right)$. Subgroup meta-analysis between patients undergoing subcutaneous versus "traditional" OT revealed no difference in ovarian cyst formation rate ((95\% CI 55-158) versus (95\% CI 84-106)). No significant heterogeneity was observed across the studies for both subgroups.

\section{Discussion}

The main aim of OT is to maintain ovarian function in premenopausal women treated with RT. It is now established as a simple and reliable method with reduced morbidity [9]. Published data vary with regards to functional outcomes such as ovarian failure, ovarian cysts and metastases to the transposed ovaries. Our systematic review of 24 studies confirms and generalizes the concept that OT is associated with a high preservation of ovarian function, an acceptable rate of ovarian cysts and a low risk of metastases in the transposed ovaries. To our knowledge, this is the first systematic review to 
Table 1 Characteristics of studies

\begin{tabular}{llccc}
\hline $\begin{array}{l}\text { First author } \\
\text { and year of } \\
\text { publication }\end{array}$ & $\begin{array}{c}\text { Study } \\
\text { design }\end{array}$ & Population & Intervention & Outcome(s) \\
up & \\
(median, \\
range)
\end{tabular}

range)

Hodel 1982 Retrospective

[7]

Husseinzadeh Prospective 1984 [20]

Women with vaginal $(n=2)$ and $=7)$ cancers

Ploch 1988 Prospective

[21]

Owens

1989 [22]

Chambers Retrospective

1990 [23]

Van Beurden Retrospective 1990 [24]

Chambers $1991[25]$

Anderson 1993 [26]

$\begin{array}{ll}\text { Bidzinski } & \text { Retrospective } \\ \text { 1993 [27] } & \\ \text { Feeney } & \text { Retrospective }\end{array}$

Retrospective

Women with cervical $(n=39)$

and vaginal $(n=1)$ cancers

Women with cervical cancer $(n=22)$

All but 3 patients had early stag cervical cancer $(n=14)$

Premenopausal women with cervical cancer stage IA and IB $(n=84)$

Women with cervical cancer $(n=44)$

Retrospective Women with stage 1 cervical cancer $(n=38)$

Retrospective Premenopausal women with early stage cervical cancer $(n=104)$

Women with stage la and $\mathrm{lb}$ carcinoma of the cervix $(n=48)$

Women with stage I-Ila cervical cancer $(n=132)$

Clough Prospective

Women with cervical cancer $(n=17)$

Covens

Retrospective

Patients with $1 \mathrm{~B}$ cervical cancer prior to radiation therapy $(n=3)$

Fujiwara Retrospective Description of a new technique for OT $1997[8]$ were included $(n=12)$

Retrospective
Open-lateral OT in patients undergoing radical
surgery followed by pelvic irradiation $(n=9)$

Open-lateral OT in patients with

$\mathrm{RH}+$ lymphadenectomy $(\mathrm{n}=22)$, primary radiotherapy alone $(n=14)$ and radiotherapy

$$
\text { following surgery }(n=4)
$$

$\mathrm{RH}$ with OT of one or both ovaries outside the pelvis $(n=5)$ followed by adjuvant radiotherapy $(n=17), B R$ only $(n=5)$ and BR + teletherapy $(n=12)$

All but one had bilateral open OT to the paracolic gutters $(n=14)$ in addition to $R H$, post-operative radiotherapy $(n=8)$

Lateral OT in addition to $\mathrm{RH}(\mathrm{n}=25)$ compared to non-OT group $(n=59)$

Open intraperitoneal OT in a lateral and cranial direction ( $n=44)$ : In 16/44 women, only one ovary could be preserved and transposed and radiotherapy $(n=6)$

Open (sc) lateral OT $(n=38)$ as part of their initial operative procedure and post-operative radiotherapy

$$
(n=14)
$$

Open-lateral OT $(n=82)$, post-operative radiotherapy $(n=24)$, comparison with non-OT group $(n=22)$

RH with OT $(n=48)$, EBRT $(n=15)$ and BR $(n=24)$

Lateral OT at the time of $\mathrm{RH}(\mathrm{n}=132)$ post-operative radiotherapy $(n=28)$

Laparoscopic unilateral OT $(n=17)$ post-operative $B R(n=14)$ and EBRT + BR $(n=3)$

Laparoscopic OT $(n=3)$ and had intarcavitary radiation desiring preservation of fertility.

Open (sc) OT ovary (benign $=15$ cancer $=12)$ and post-operative EBRT $(n=10)$ and $B R(n=1)$

Laparoscopic OT

Ovarian function by clinical symptoms
and FSH levels

Ovarian function by FSH, LH levels, 15/22 from surgery only group were included

for which FSH levels were available

Ovarian function by FSH, LH, E2 and progesterone levels, additional analysis of location of transposed ovaries

Oestrogen deficiency symptoms, metastatic disease or required reoperation secondary to new ovarian pathology.

Symptomatic ovarian cysts and symptoms of menopause by FSH and LH levels

Menopausal symptoms, measurement of FSH where available $(n=6)$

Ovarian function by $\mathrm{FSH} / \mathrm{LH}$, ovarian preservation directly related to estimated scattered dose to ovaries, symptomatic ovarian cysts by USS

Retention of ovarian function, symptomatic ovarian cysts and metastases

Effect on ovarian function

Menopausal symptoms, FSH levels and adnexal pathology, Ovarian function is reserved only in $50 \%$ of patients with post-operative BR

Evaluation of ovarian function by clinical and laboratory criteria, 100\% ovarian preservation in patients younger than 40 years old

Menstruating regularly after completion of treatment with serum FSH in the normal premenopausal range.

Cyst formation, symptoms of menopause with FSH levels measurement

Ovarian function, cysts and prognosis for fertility

35

24 
Table 1 Characteristics of studies (Continued)

\begin{tabular}{|c|c|c|c|c|c|}
\hline $\begin{array}{l}\text { Morice 1998a } \\
{[30]}\end{array}$ & & $\begin{array}{l}\text { Women with } 27 \text { vaginal cancers, } 9 \text { ovarian } \\
\text { dysgerminomas and } 1 \text { pelvic sarcoma }\end{array}$ & & & \\
\hline $\begin{array}{l}\text { Morice 1998b } \\
\text { [31] }\end{array}$ & Prospective & $\begin{array}{c}\text { Only 14/ } 24 \text { were included as they were } \\
\text { repeated in other paper published by the } \\
\text { same author and } 4 \text { non gyanecological } \\
\text { malignancies, } 12 \text { clear cell vaginal and } \\
\text { cervical cancers, } 1 \text { vaginal adenocarcinoma, } \\
1 \text { dysgerminoma }\end{array}$ & $\begin{array}{c}\text { Laparoscopic OT }(n=14), B R(n=13) \\
\text { and EBRT }(n=5)\end{array}$ & $\begin{array}{l}\text { Clinical and laboratory follow-up tests of } \\
\text { ovarian function and clinical pregnancies. }\end{array}$ & 6 \\
\hline $\begin{array}{l}\text { Morice } 2000 \\
\text { [32] }\end{array}$ & Prospective & Women with cervical cancer $(n=107)$ & $\begin{array}{c}\text { Laparoscopic bilateral OT to the paracolic } \\
\text { gutters with RH and lymphadenectomy only } \\
(n=11) \text {, with } 60 \text { Gy of vaginal BR along with } \\
\text { surgery ( } n=59 \text { ) or surgery, BR and } 45 \\
\text { Gy of EBRT }(n=25)\end{array}$ & $\begin{array}{l}\text { Ovarian function: by clinical symptoms, } \\
\text { FSH, E2 level, } 12 \text { patients were lost to } \\
\text { follow up, ovarian cysts: by USS }\end{array}$ & $31(10-56)$ \\
\hline $\begin{array}{l}\text { Buekers } 2001 \\
\text { [33] }\end{array}$ & Retrospective & Women with cervical cancer $(n=80)$ & $\begin{array}{l}\text { Open OT to one or both ovaries at the time } \\
\text { of exploration for } \mathrm{RH} \text { or staging } \\
\text { lymphadenectomy, postoperative } \\
\text { irradiation }(n=26)\end{array}$ & $\begin{array}{l}\text { Ovarian function by FSH, report of cyclic } \\
\text { signs and menopausal symptoms, analysis } \\
\text { of estrogen effect to vaginal epithelium }\end{array}$ & $\begin{array}{l}85(43- \\
126)\end{array}$ \\
\hline $\begin{array}{l}\text { Olejek } 2001 \\
{[34]}\end{array}$ & Retrospective & $\begin{array}{l}\text { Women with cervical cancer for which } \\
\text { follow up was available }(n=44)\end{array}$ & $\begin{array}{l}\text { Open OT, comparison of ovarian preservation } \\
\text { between RT and non-RT groups }\end{array}$ & $\begin{array}{l}\text { Ovarian function by FSH, LH, E2, PRL, } \\
\text { testosterone, ovarian cysts by USS }\end{array}$ & 60 \\
\hline $\begin{array}{l}\text { Yamamoto } \\
2001[10]\end{array}$ & Prospective & $\begin{array}{c}\text { Women with cervical cancer }(n=56) \\
\text { Regression analysis of risk factors for ovarian } \\
\text { metastases }\end{array}$ & $\begin{array}{l}\text { Open OT during RH only }(n=30) \text {, } \\
\text { with pelvic irradiation }(n=26)\end{array}$ & $\begin{array}{l}\text { Ovarian function by basal bosy temperature, } \\
\text { FSH, E2 and PG, regression analysis of risk } \\
\text { factors for ovarian metastases }\end{array}$ & 12 \\
\hline $\begin{array}{l}\text { Nagao } 2006 \\
{[35]}\end{array}$ & Retrospective & $\begin{array}{l}\text { Comparison between OT }(n=27) \text { and } 2 \text { non- } \\
\text { OT groups }(n=59) \text { for ovarian preservation }\end{array}$ & Open OT following RH $(n=27)$ & Ovarian function by FSH & 65 \\
\hline $\begin{array}{l}\text { Pahisa } 2008 \\
\text { [36] }\end{array}$ & Prospective & Women with 1 b1 cervical cancer $(n=28)$ & $\begin{array}{l}\text { Laparoscopic OT with no RT }(n=16) \\
\text { BR }(n=7) \text { and EBRT }+B R(n=5)\end{array}$ & $\begin{array}{l}\text { Ovarian function by clinical symptoms and } \\
\text { FSH and E3; follow up available for } \\
24 / 28 \text { patients, ovarian cysts by annual } \\
\text { surveillance abdominal CT }\end{array}$ & 44 \\
\hline $\begin{array}{l}\text { Al-Badawi } \\
2010[37]\end{array}$ & Retrospective & Women with cervical cancer $(n=15)$ & $\begin{array}{l}\text { Bilateral laparoscopic OT to the paracolic } \\
\text { gutters with uterine preservation followed } \\
\text { by pelvic irradiation }(n=15)\end{array}$ & Ovarian function by clinical symptoms and FSH & 33 \\
\hline Han 2011 [38] & Retrospective & $\begin{array}{l}\text { Women with cervical cancer }(n=29) \text {, } \\
\text { comparison with non-OT group }\end{array}$ & $\begin{array}{l}\text { OT in cervical cancer patients }(n=29) \\
\text { prior to pelvic irradiation }\end{array}$ & $\begin{array}{c}\text { Ovarian function by E2 and FSH, 19/29 } \\
\text { patients were included for which hormonal } \\
\text { levels were available }\end{array}$ & 17.2 \\
\hline $\begin{array}{l}\text { Hwang } 2012 \\
\text { [39] }\end{array}$ & Retrospective & $\begin{array}{l}\text { Women with cervical cancer }(n=53) \text {, } \\
39 / 53 \text { patients were included }\end{array}$ & $\begin{array}{c}\text { Open }(n=19) \text { and laparoscopic }(n=34) \text { OT } \\
\text { to the paracolic gutters with primary } \\
\text { chemoradiotherapy only }(n=3) \text {, with RH } \\
\text { and lymphadenectomy }(n=33) \text { followed by } \\
\text { adjuvant RT }(n=23) \text {, with lymphadenectomy followed by } \\
\text { primary chemoradiotherapy }(n=17)\end{array}$ & $\begin{array}{l}\text { Ovarian function by clinical symptoms } \\
\text { and FSH, } 14 / 53 \text { patients were lost on } \\
\text { follow up or FSH not available }\end{array}$ & 39.8 \\
\hline
\end{tabular}




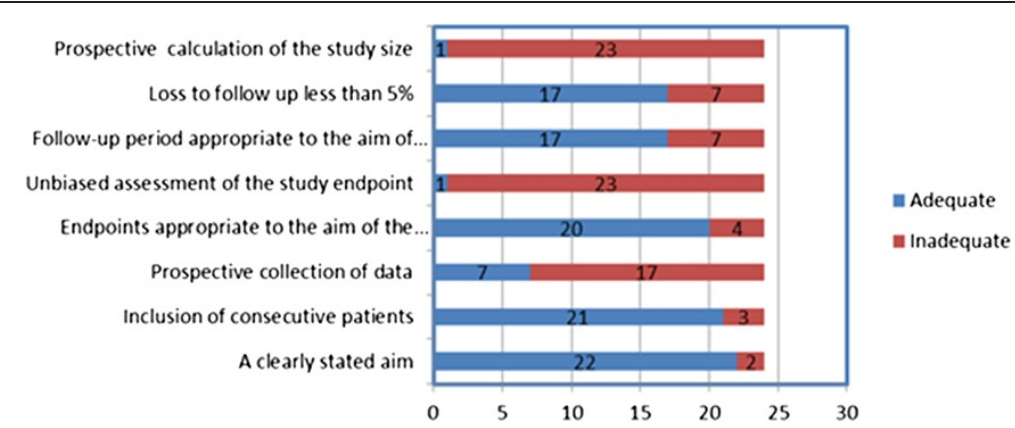

Figure 2 Quality assessment of the observational studies (MINORS criteria).

provide an overview of the efficacy of OT on the aforementioned outcomes.

Selection of patients with early cervical and other gynaecological cancers who would benefit from OT is challenging, as difficulty arises to decide which patients would require postoperative RT prior to the surgical procedure [40]. To overcome this problem, we examined 3 treatment groups: Group A consisted of those patients who had surgery only. Patients in group B had postoperative BR. Group C consisted of patients who had primarily EBRT following surgery $\pm \mathrm{BR}$. OT was the fixed variable for all groups. In the absence of control groups for each treatment modality, the approach allowed for an indirect comparison amongst surgery, BR and EBRT without the risk of increasing missing data.
Following a comprehensive search strategy, we employed the MINORS criteria, as indicated for quality assessment of the included observational non-comparative studies. We took into account the specific weight of the studies and after checking for heterogeneity, we employed a random-effects model to combine the data across studies to control variability. However, the majority of studies were of retrospective design. They were all observational; hence most were not designed for the specific outcomes examined with the exception of ovarian function. There was little evidence of publication bias as shown by the funnel-plot symmetry (Figure 6). The primary studies did not stratify their results by confounding factors such as age and follow up and hence, adjustment for these factors was not possible. Therefore, a certain degree of clinical heterogeneity should be expected.

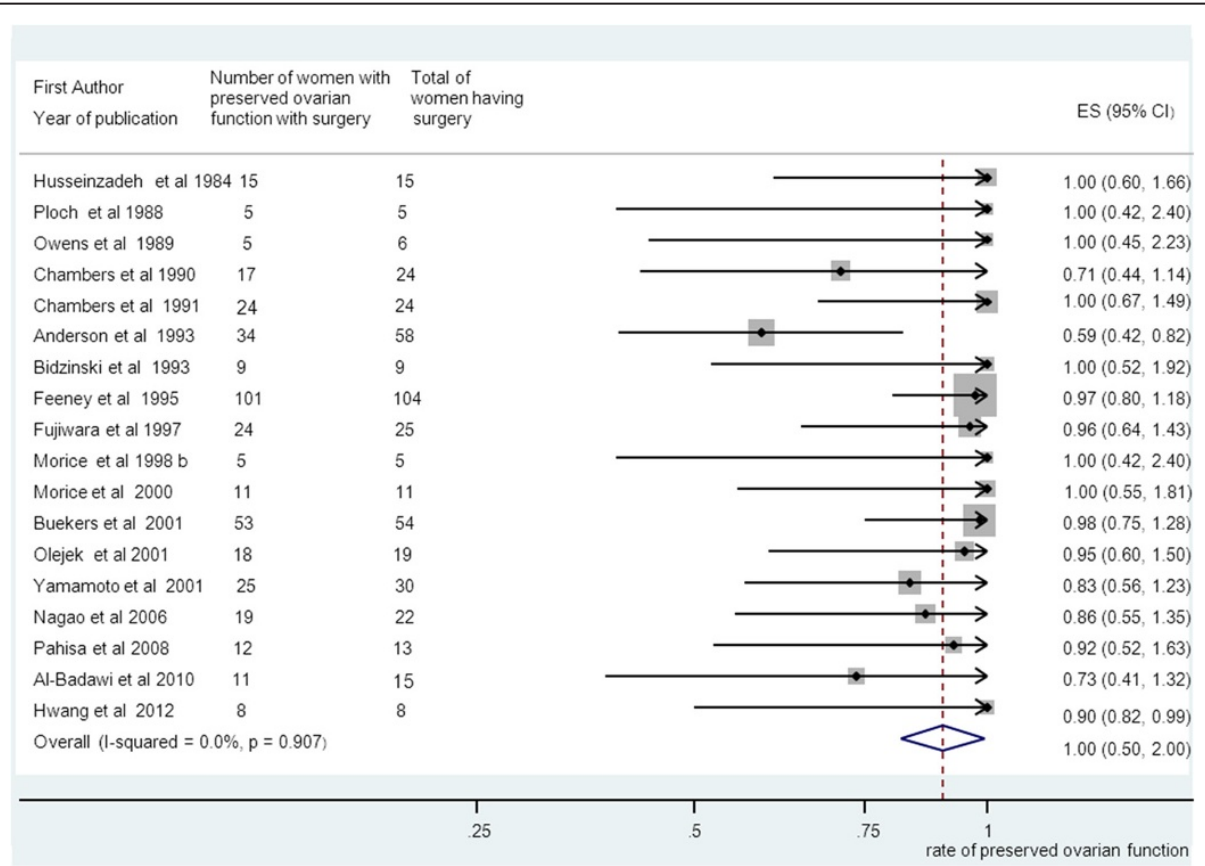

Figure 3 Ovarian preservation and surgery only group. Forest plot showing the proportions of women (with confidence intervals) with preserved ovarian function following ovarian transposition who had surgery alone. 


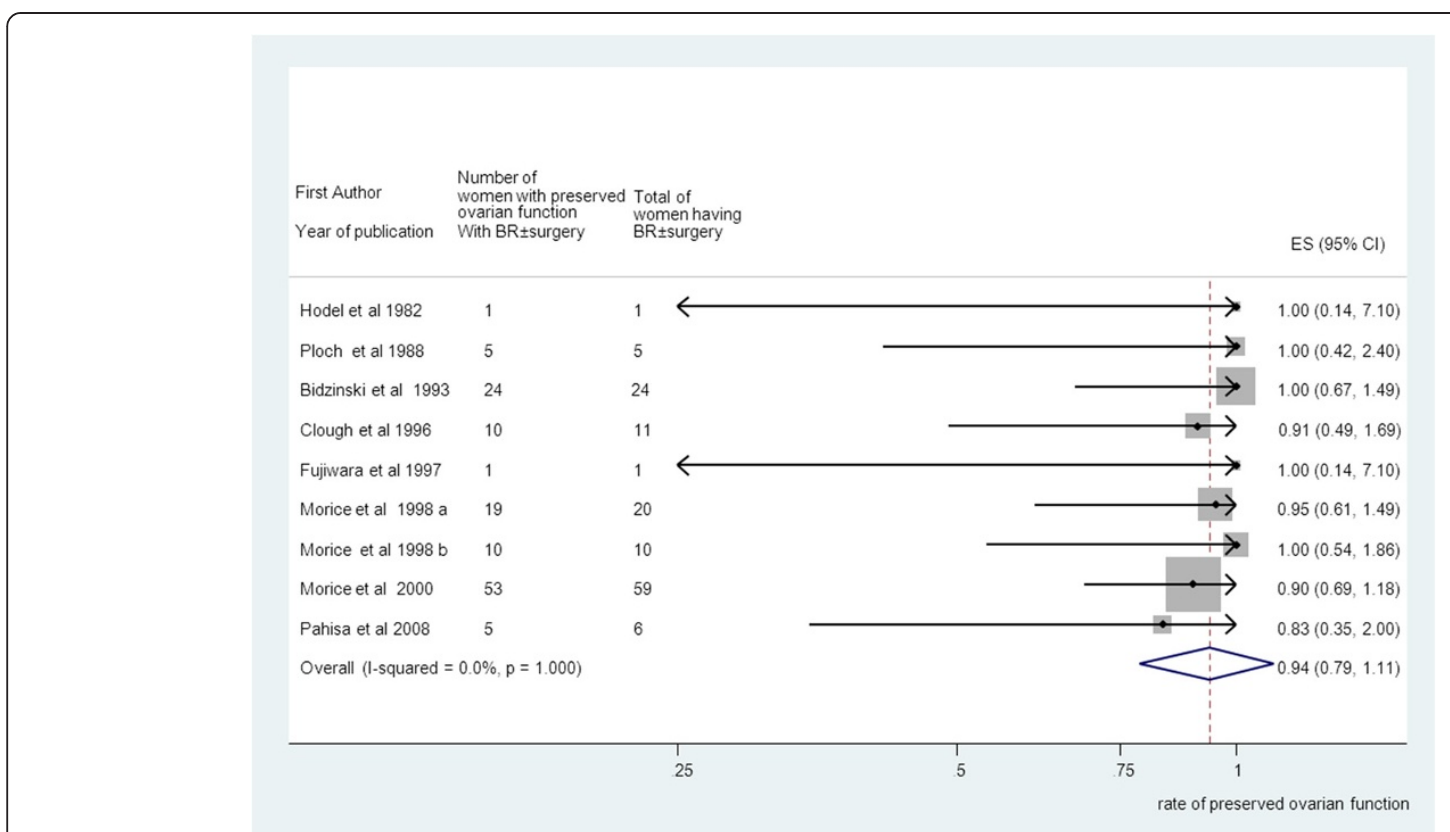

Figure 4 Ovarian preservation and brachytherapy (BR) \pm surgery group. Forest plot showing the proportions of women (with confidence intervals) with preserved ovarian function following ovarian transposition who had brachytherapy (BR) \pm surgery.

In our studies, ovarian function was assessed by patient's symptoms and serum FSH levels. Ovarian dose tolerance depends on volume irradiated, total radiation dose and the fractionation schedule in addition to patient's age at the time of treatment. A fractionated dose exceeding 24 Gy to the ovaries can produce permanent ovarian ablation [41]. We demonstrated that ovarian function was highly preserved in those patients who had no adjuvant RT irrespective of the type of transposition or the position of transposed ovaries [25]. Only $10 \%$ of

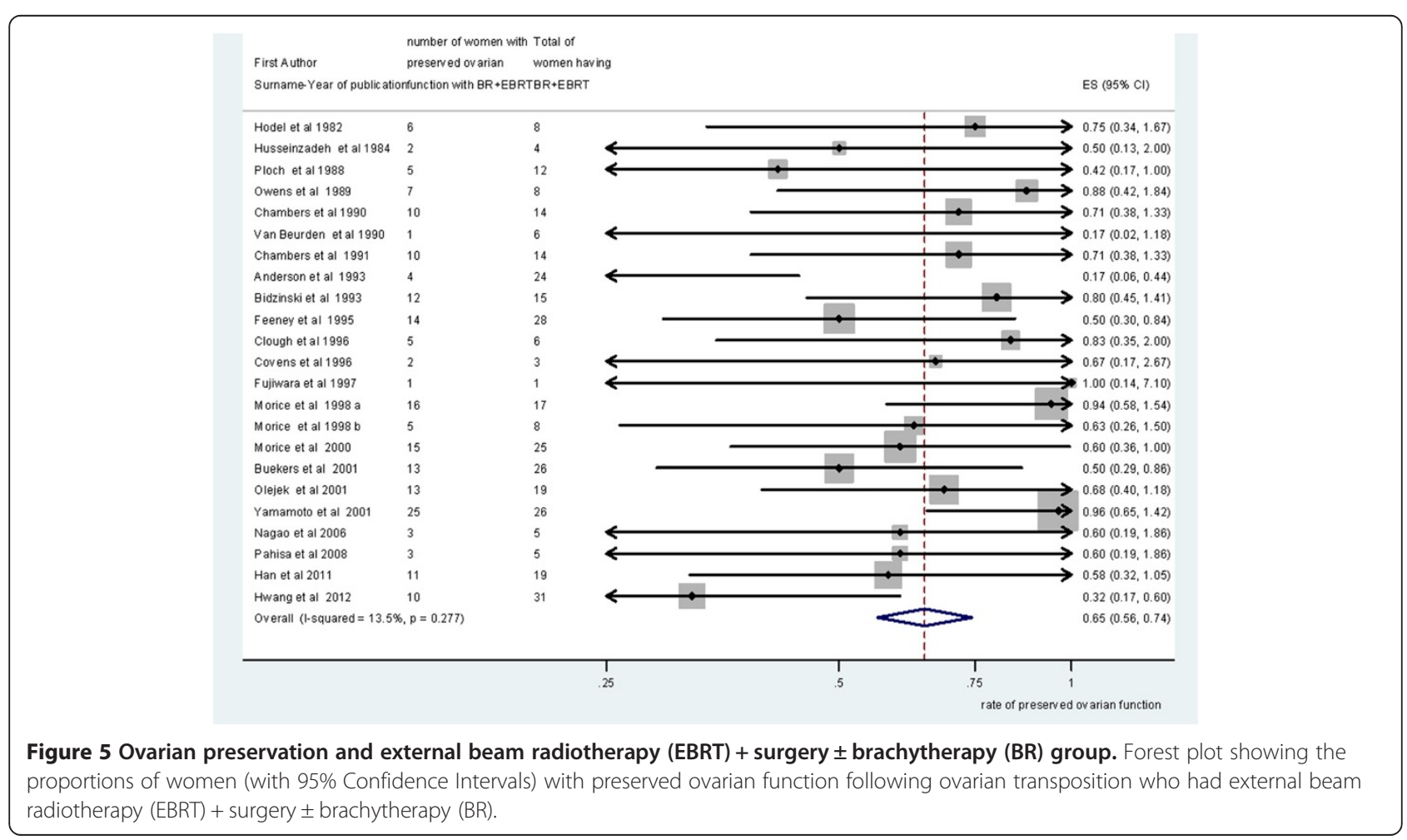




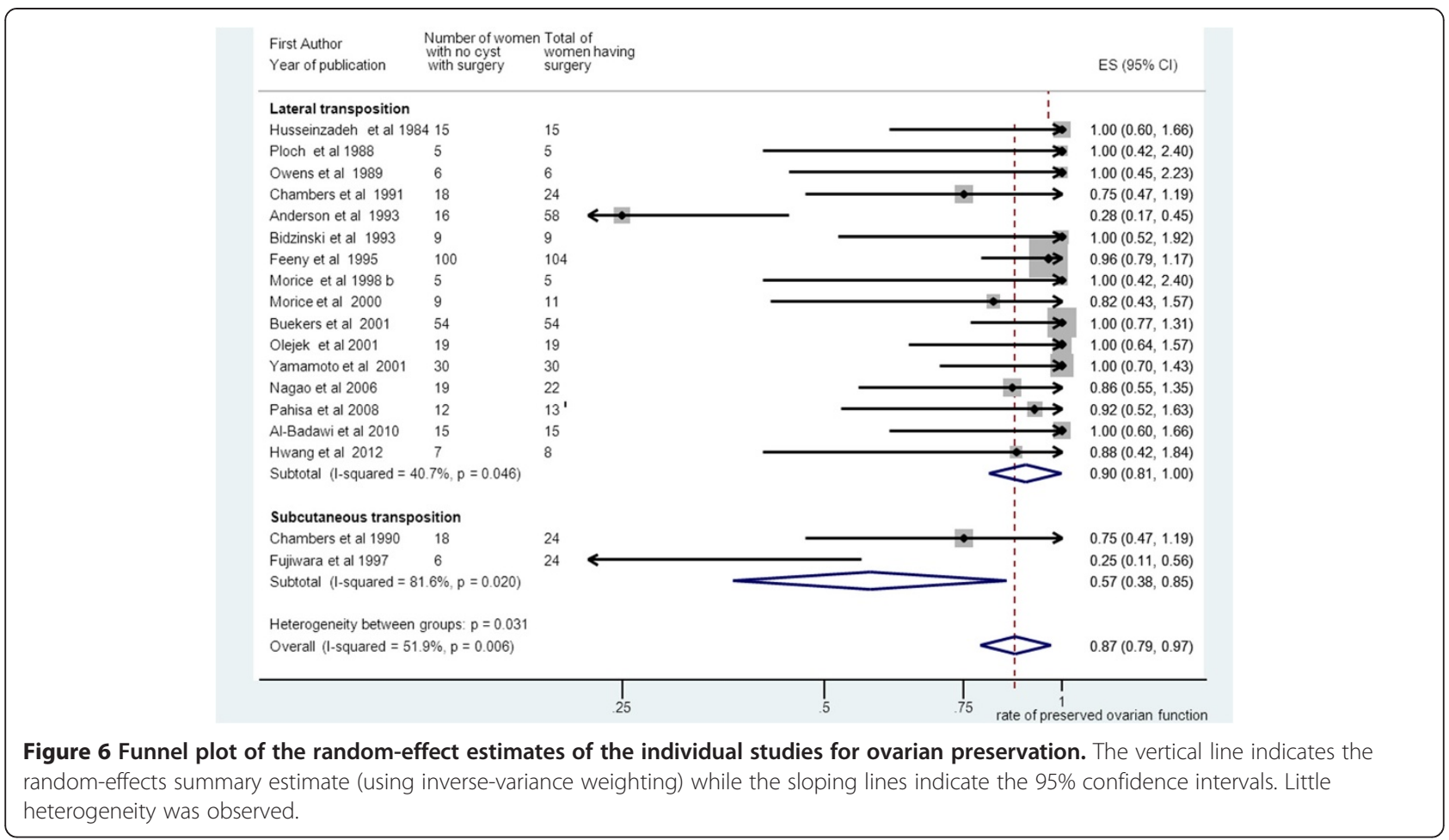

patients in that group became menopausal whilst theoretically they should be $5 \%$ or less [42]. Notably, those patients who had BR \pm surgery (group B) performed as good as the surgery only group (group A). However, the strength of this inference may be reduced by the wider confidence intervals in this group due to smaller numbers of patients. While, the proportions of patients who had BR with intact uterus in group B is not known, we speculate a "timing effect" of the OT prior to irradiation as opposed to simultaneously at surgery. If OT takes place at the time of an extensive surgery, the risk for vascular compromise to the ovary from trauma or RH should be higher. Yet, the

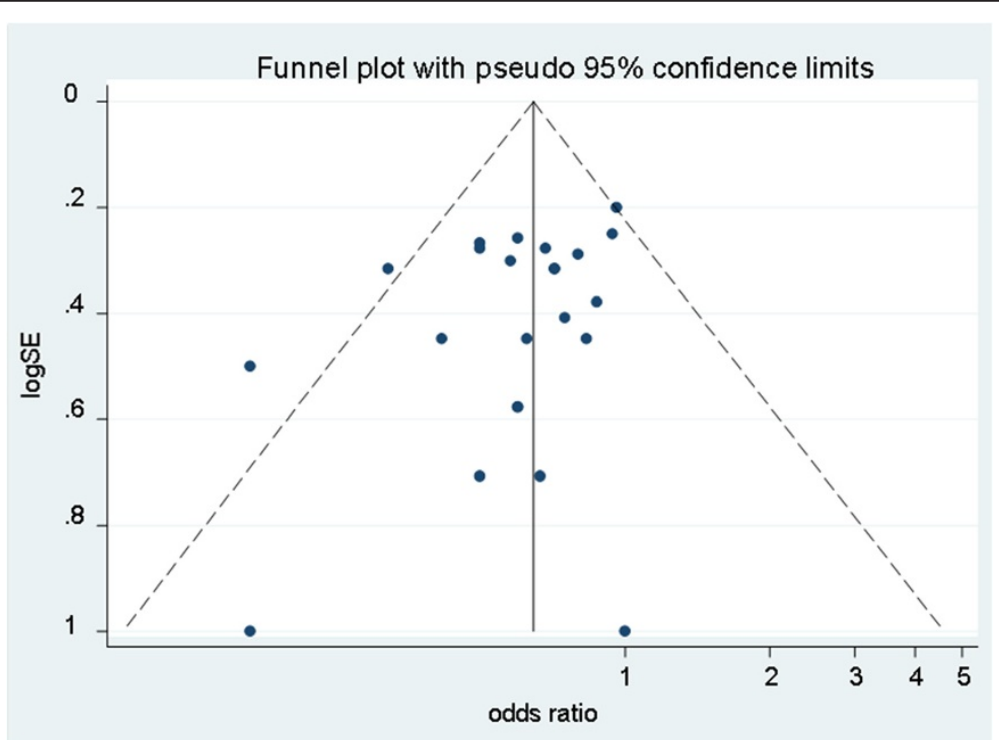

Figure 7 Subgroup meta-analysis for no ovarian cyst formation and surgery group alone. Forest plot showing the proportions of women (with 95\% Confidence Intervals) with no ovarian cysts between subgroups of those with lateral ovarian transposition versus subcutaneous ovarian transposition. All patients had surgery alone. 
incidence of ovarian failure appears to be related to the length of follow up with 7\% failing within 3 years and up to $50 \%$ within 5 years [22]. We noted that mean follow up in group B was shorter compared to group A, which might be partly responsible for the performance of the BR group. Notably, we observed that ovarian function was better preserved in those patients who have BR only without EBRT, consistent with the study by Morice et al. [32]. A plausible speculation for this is that EBRT may be damaging the vascular supply to the ovary as it loops down the pelvic brim before ascending again out of the brim to the transposed position. Therefore, if transposing an ovary prior to EBRT great care should be made to transpose the pedicle in addition to the ovary.

Further comparison between OT and non-OT cancer groups is required to assess directly the efficacy of OT for ovarian function preservation. However, considering that older women appear more susceptible to permanent ovarian damage compared to young women, it is expected that the incidence of ovarian failure following anticancer treatment ranges between 30-50\% [43]. Therefore, although a direct comparison was not possible in the absence of non-OT cancer groups, we report an apparent benefit from OT for all treatment groups.

We demonstrated that the risk of ovarian carcinoma affecting the transposed ovaries is extremely low. Several risk factors for ovarian involvement have been suggested [15]. It appears that non-squamous histology carries a higher risk than the squamous one. Sutton et al. reported an incidence of $0.5 \%$ in squamous cell carcinoma compared to $1.7 \%$ in adenocarcinoma [44]. Therefore, ovarian metastasis in early cervical cancer occurs very rarely [45]. Moreover, the incidence of port site metastasis is $<1 \%$ [32], which would explain our results, as the majority of transpositions were performed laparoscopically.

Risk factors for cyst development include previous surgery, extensive ovarian mobilisation albeit the mechanism is unknown and gynaecological pathology such as endometriosis or pelvic inflammatory disease [23]. In that respect, It is not surprising that the incidence of ovarian cyst formation in the transposed ovaries was common in the surgery only group (13\%). In the subgroup meta-analysis, the possible advantages of subcutaneous transposition such as early detection and easier diagnosis of ovarian cysts, easy surgical access to remove ovarian cysts and facilitation of in vitro fertilization [8] were outweighed by a trend towards higher rate of ovarian cyst formation (43\%) possibly due to the more extensive ovarian mobilisation at the time of subcutaneous transposition [23]. The risk for cyst formation was comparable to the BR group. As expected, only 5\% of patients in the EBRT group had ovarian cysts because of the well-established association between menopausal status and ovarian cyst formation. Symptomatic cysts were identified by imaging and were treated either conservatively or surgically. Surgical treatment included needle puncture, cystectomy or oophorectomy. Conservative treatment included analgesics, hormonal or expectant management.

In conclusion, we confirm the efficacy of OT in patients undergoing radio-surgical treatment of gynaecological malignancies with high preservation of ovarian function and negligible risk of metastases to the transposed ovaries despite rather common incidence of ovarian cysts. Surgery alone and post-operative BR groups performed best for the above outcomes. As quality of care remains an important issue in cancer care, careful expansion of patient selection could identify those premenopausal patients who would really benefit from this rather underutilised procedure.

\section{Competing interests}

The authors declare that they have no competing interest.

\section{Authors' contributions}

KG participated in the study design, conducted the literature search, extracted the data and authored the manuscript. AL reviewed the extracted data, drafted the manuscript and participated in the data analysis. IG performed the data analysis and revised the manuscript. PP and $\mathrm{KH}$ critically appraised and revised the manuscript. TI conceptualized the study, participated in the primary analysis and revised the manuscript. All authors read and approved the final manuscript.

\section{Acknowledgements}

We would like to thank Ahmed Ahmed and Katie Herbert for constructive discussions.

\section{Author details}

${ }^{1}$ Gynaecologic Oncology Unit, Churchill Hospital, Oxford University Hospitals NHS Trust, Oxford, UK. '2Department of Gynaecologic Oncology, Royal Marsden Hospital NHS Trust, London, UK. ${ }^{3}$ School of Clinical and Experimental Medicine, College of Medical and Dental Sciences, University of Birmingham, Birmingham, UK.

Received: 30 April 2014 Accepted: 16 June 2014

Published: 25 June 2014

\section{References}

1. McCall ML, Keaty EC, Thompson JD: Conservation of ovarian tissue in the treatment of the carcinoma of the cervix with radical surgery. Am J Obstet Gynecol 1958, 75:590-600.

2. lavazzo C, Darlas FM, Ckegkes ID: The role of robotics in ovarian transposition. Acta Inform Med 1958, 21(2):135-7. doi:10.5455/aim.2013.21.135-137.

3. Kwik M, O'Neill A, Hamani Y, Chapman M, Chou D: Laparoscopic ovarian transposition with potential preservation of natural fertility. J Minim Invasive Gynecol 2010, 17(4):411-2. doi:10.1016/j.jmig.2009.07.002.

4. Krebs C, Blixenkrone-Moller N, Mosekilde V: Preservation of ovarian function in early cervical cancer after surgical uplifting of the ovaries and radiation therapy. Acta Radiologica (Therapy) 1963, 1:176-182.

5. Nahhas WA, Nisce LZ, D'Angio GJ, Lewis JL: Lateral ovarian transposition. Obstet Gynecol 1971, 38:785-788.

6. Gareer W, Gad Z, Gareer H: Needle oophoropexy: a new simple technique for ovarian transposition prior to pelvic irradiation. Surg Endosc 2011, 25(7):2241-6.

7. Hodel K, Rich WM, Austin P, DiSaia PJ: The role of ovarian transposition in conservation of ovarian function in radical hysterectomy followed by pelvic radiation. Gynecol Oncol 1982, 13:195-202.

8. Fujiwara K, Mohri H, Yoshida T, Yamauchi H, Kohno I: Subcutaneous transposition of the ovary following hysterectomy. Int J Gynecol Obstet 1997, 58(2):223-228. 
9. Clough KB, Goffinet F, Labib A, Renolleau C, Campana F, de la Rochefordiere A, Durand JC: Laparoscopic unilateral ovarian transposition prior to irradiation: prospective study of 20 cases. Cancer 1996, 77(12):2638-45

10. Yamamoto R, Okamoto K, Yukiharu T, Kaneuchi M, Negishi H, Sakuragi N, Fujimoto S: A study of risk factors for ovarian metastases in stage Ib-Illb cervical carcinoma and analysis of ovarian function after a transposition. Gynecol Oncol 2001, 82:312-6.

11. Cowles RA, Gewanter RM, Kandel JJ: Ovarian repositioning in pediatric cancer patients: Flexible techniques accommodate pelvic radiation fields. Pediatr Blood Cancer 2007, 49:339-41.

12. Williams RS, Littell RD, Mendenhall NP: Laparoscopic oophoropexy and ovarian function in the treatment of Hodgkin disease. Cancer 1999, $86: 2138-42$

13. Kurt M, Uncu G, Cetintas SK, Kucuk N, Guler S, Ozkan L: Successful spontaneous pregnancy in a patient with rectal carcinoma treated with pelvic radiotherapy and concurrent chemotherapy: the unique role of laparoscopic lateral ovary transposition. Eur J Gynaecol Oncol 2007, 28(5):408-10.

14. Steigrad S, Hacker NF, Kolb B: In vitro fertilization surrogate pregnancy in a patient who underwent radical hysterectomy followed by ovarian transposition, lower abdominal wall radiotherapy, and chemotherapy. Fertil Steril 2005, 83:1547-9

15. Landoni F, Zanagnolo V, Lovato-Diaz L, Maneo A, Rossi R, Gadducci A, Cosio S, Maggino T, Sartori E, Tisi C, Zola P, Marocco F, Botteri E, Ravanelli K, Cooperative Task Force: Ovarian metastases in early-stage cervical cancer (IA2-IIA): a multicenter retrospective study of 1965 patients. Int J Gynecol Cancer 2007, 17:623-8.

16. Slim K, Nini E, Forestier D, Kwiatkowski F, Panis Y, Chipponi J: Methodological index for non-randomized studies (minors): development and validation of a new instrument. ANZ J Surg 2003, 73:712-6.

17. Stroup DF, Berlin J, Morton S, Olkin I, Williamson D, Rennie D, Moher D, Becker B, Sipe TA, Thacker S: Meta-analysis of observational studies in epidemiology: a proposal for reporting. Meta-analysis Of Observational Studies in Epidemiology (MOOSE) group. JAMA 2000, 283(15):2008-2012.

18. Dursun P, Ayhan A, Yanik FB, Kuşçu E: Ovarian transposition for the preservation of ovarian function in young patients with cervical carcinoma. Eur J Gynaecol Oncol 2009, 30(1):13-5.

19. Stroud JS, Mutch D, Rader J, Powell M, Thaker PH, Grigsby PW: Effects of cancer treatment on ovarian function. Fertil Steril 2009, 92(2):417-27.

20. Husseinzadeh N, Nahhas WA, Velkley DE, Whitney CW, Mortel R: The preservation of ovarian function in young women undergoing pelvic radiation therapy. Gynecol Oncol 1984, 18:373-9.

21. Ploch E, Kietlinska Z, Kawczynska M: Evaluation of the hormonal function of transposed ovaries in cervical cancer patients after surgery and pelvic irradiation. Eur J Gynaecol Oncol 1988, 9(6):479-84.

22. Owens S, Roberts WS, Fiorica JV, Hoffman MS, LaPolla JP, Cavanagh D: Ovarian management at the time of radical hysterectomy for cancer of the cervix. Gynecol Oncol 1989, 35(3):349-51.

23. Chambers SK, Chambers JT, Holm C, Peschel RE, Schwartz PE: Sequelae of lateral ovarian transposition in unirradiated cervical cancer patients. Gynecol Oncol 1990, 39(2):155-9.

24. Van Beurden M, Schuster-Uitterhoeve AL, Lammes FB: Feasibility of transposition of the ovaries in the surgical and radiotherapeutical treatment of cervical cancer. Eur J Surg Oncol 1990, 16(2):141-6.

25. Chambers SK, Chambers JT, Kier R, Peschel RE: Sequelae of lateral ovarian transposition in irradiated cervical cancer patients. Int J Radiat Oncol Biol Phys 1991, 20(6):1305-8.

26. Anderson B, LaPolla J, Turner D, Chapman G, Buller R: Ovarian transposition in cervical cancer. Gynecol Oncol 1993, 49(2):206-14

27. Bidziński M, Lemieszczuk B, Zieliński J: Evaluation of the hormonal function and features of the ultrasound picture of transposed ovary in cervical cancer patients after surgery and pelvic irradiation. Eur J Gynaecol Oncol 1993, 14:77-80.

28. Feeney DD, Moore DH, Look KY, Stehman FB, Sutton GP: The fate of the ovaries after radical hysterectomy and ovarian transposition. Gynecol Oncol 1995, 56(1):3-7.

29. Covens AL, van der Putten HW, Fyles AW, Leung PM, O'Brien PF, Murphy KJ, DePetrillo AD: Laparoscopic ovarian transposition. Eur J Gynaecol Oncol 1996, 17(3):177-82
30. Morice P, Thiam-Ba R, Castaigne D, Haie-Meder C, Gerbaulet A, Pautier P, Duvillard $P$, Michel G: Fertility results after ovarian transposition for pelvic malignancies treated by external irradiation or brachytherapy. Hum Reprod 1998, 13(3):660-3.

31. Morice P, Castaigne D, Haie-Meder C, Pautier P, El Hassan J, Duvillard P, Gerbaulet A, Michel G: Laparoscopic ovarian transposition for pelvic malignancies: indications and functional outcomes. Fertil Steril 1998, 70(5):956-60.

32. Morice P, Juncker L, Rey A, El-Hassan J, Haie-Meder C, Castaigne D: Ovarian transposition for patients with cervical carcinoma treated by radiosurgical combination. Fertil Steril 2000, 74(4):743-8.

33. Buekers TE, Anderson B, Sorosky Jl, Buller RE: Ovarian function after surgical treatment for cervical cancer. Gynecol Oncol 2011, 80(1):85-8.

34. Olejek A, Wala D, Chimiczewski P, Rzempoluch J: Hormonal activity of transposed ovaries in young women treated for cervical cancer. Gynecol Endocrinol 2001, 15(1):5-13.

35. Nagao S, Fujiwara K, Ishikawa H, Oda T, Tanaka K, Aotani E, Kohno I: Hormonal function after ovarian transposition to the abdominal subcutaneous fat tissue. Int J Gynecol Cancer 2006, 16(1):121-4.

36. Pahisa J, Martínez-Román S, Martínez-Zamora MA, Torné A, Caparrós X, Sanjuán A, Lejárcegui JA: Laparoscopic ovarian transposition in patients with early cervical cancer. Int J Gynecol Cancer 2008, 18(3):584-9.

37. Al-Badawi IA, Al-Aker M, Al-Subhi J, Salem H, Abduljabbar A, Balaraj K, Munkarah A: Laparoscopic Ovarian Transposition Before Pelvic Irradiation: A Saudi Tertiary Center Experience. Int J Gynecol Cancer 2010, 20(6):1082-1086.

38. Han SS, Kim YH, Lee SH, Kim GJ, Kim HJ, Kim JW, Park NH, Song YS, Kang SB: Underuse of ovarian transposition in reproductive-aged cancer patients treated by primary or adjuvant pelvic irradiation. $J$ Obstet Gynaecol Res 2011, 37(7):825-9. doi:10.1111/j.1447-0756.2010.01443.x.

39. Hwang JH, Yoo HJ, Park SH, Lim MC, Seo SS, Kang S, Kim JY, Park SY: Association between the location of transposed ovary and ovarian function in patients with uterine cervical cancer treated with (postoperative or primary) pelvic radiotherapy. Fertil Steril 2012, 97(6):1387-93.

40. Waggoner SE: Cervical cancer. Lancet 2003, 361:2217-25.

41. Grigsby PW, Russell A, Bruner D, Eifel P, Koh WJ, Spanos W, Stetz J, Stitt JA, Sullivan J: Late injury of cancer therapy on the female reproductive tract. Int J Radiat Oncol Biol Phys 1995, 31(5):1281-99.

42. Coulam CB, Adamson SC, Annegers JF: Incidence of premature ovarian failure. Obstet Gynecol 1986, 67(4):604-6.

43. Goodwin P, Ennis M, Pritchard K, Trudeau M, Hood N: Risk of menopause during the first year after breast cancer diagnosis. J Clin Oncol 1999, $17: 2365-9$

44. Sutton GP, Bundy BN, Delgado G, Sevin BU, Creasman WT, Major FJ, Zaino R: Ovarian metastases in stage IB carcinoma of the cervix: a Gynecologic Oncology Group study. Am J Obstet Gynecol 1992, 166:50-3.

45. Shimada M, Kigawa J, Nishimura R, Yamaguchi S, Kuzuya K, Nakanishi T, Suzuki M, Kita T, Iwasaka T, Terakawa N: Ovarian metastasis in carcinoma of the uterine cervix. Gynecol Oncol 2006, 101(2):234-7.

doi:10.1186/1757-2215-7-69

Cite this article as: Gubbala et al:: Outcomes of ovarian transposition in gynaecological cancers; a systematic review and meta-analysis. Journal of Ovarian Research 2014 7:69.

\section{Submit your next manuscript to BioMed Central and take full advantage of:}

- Convenient online submission

- Thorough peer review

- No space constraints or color figure charges

- Immediate publication on acceptance

- Inclusion in PubMed, CAS, Scopus and Google Scholar

- Research which is freely available for redistribution 